Pat Thomson

Jodie Pennacchia

The University of Nottingham

\begin{abstract}
In schools, the notion of 'care is often synonymous with welfare and disciplinary regimes. Drawing on Foucault, and a study of alternative education across the UK, and looking in depth at two cases of complementary alternative education, we identify three types of disciplinary regimes at work in schools: (1) dominant performative reward and punishment, (2) team building and (3) therapeutic. We argue that while all three regimes aim to steer identified students back to the norm, the two complementary approaches that we saw avoided the narrow instrumental behaviourist approaches of the dominant pattern. In so doing, they also opened up wider horizons of possibility and ways to be and become.
\end{abstract}




\section{DISCIPLINARY REGIMES OF 'CARE' AND COMPLEMENTARY ALTERNATIVE EDUCATION}

The notion of care is ubiquitous to alternative education, as well as to what Roger Slee helpfully calls 'regular schools' (Slee, 2011). Researchers around the world, and working across disciplines, regularly report that young people in alternative education settings experience far greater levels of care than in their former school (Aron, 2006; Denny, Fleming, Clark, \& Wall, 2004; Guerin \& Denti, 1999; Kim \& Taylor, 2008; Raywid, 1994). Noddings (1992) and Fielding (2006) see care in contemporary schooling operating either in support of instrumentalism or personcentred-ness. We share their concern about instrumentalist uses of care but seek to trouble a binary view. Our paper examines the ways in which care is manifest in complementary alternative education provision, as part of the organisation of welfare and discipline in a school. Our interest is primarily in differences in alternative educational organisational regimes and what this might suggest about, and for, both regular and alternative education.

We draw on a Foucauldian conceptual frame in order to consider how schools keep order, and outline the dominant mode of performative reward and punishment discipline that we saw in alternative education in a recent national study. We then present two short-term alternative programmes - one 'team-building and training' and the other therapeutic in approach. We suggest that these two programmes appear to suffer less from the performative push that dominates both regular schools and alternative education. We speculate on the implications of these differences. We begin with a brief discussion of alternative and complementary education.

\section{Alternative and complementary alternative education}

Alternative education ( $\mathrm{AE}$ ) is defined in English law not by its pedagogy but by its enrolment. $A E$ is designated specifically

... for pupils who, because of exclusion, illness or other reasons, would not otherwise receive suitable education; education arranged by schools for pupils on a fixed period exclusion; and pupils being directed by schools to off-site provision to improve their behaviour.

(http://www.education.gov.uk/aboutdfe/statutory/)

A vast array of sites and services offer alternative education. Some is full-time and long term, some full-time and shorter-term (one to three terms), and there is also part-time provision of various durations. Part-time provision is intended to contribute to a young person's educational programme and is thus known as 'complementary'.

Complementary AE varies enormously, ranging from short-term interventions geared to change behaviour to the provision of vocational education which offers 
specific training and qualifications. Complementary programmes are offered both on and off the school site, and by a range of providers, including charities, further education and schools themselves. Schools might for instance purchase places in complementary programmes provided by others, commission a programme for their students, or establish and run programmes in-house.

In England, the allocation of 'pupil premium' funding to schools, specific funding designed to allow them to provide additional support and services to young people they deem at risk of failure, has created both incentive for, and increased interest in, complementary programmes. Cuts to local authority provision, the development of school-run collaborative processes for young people excluded from school, the growth of 'managed moves' programmes (Abdelnoor, 2007; Harris, Vincent, Thomson, \& Toalster, 2006; Vincent, Harris, Thomson, \& Toalster, 2007) and a recent trial to test out schools' capacity to commission all of their own alternative education provision (Institute of Education (University of London) and the National Foundation for Educational Research (NFER), 2013) have all contributed to a significant increase in complementary $A E$. This expanded $A E$ is either run by schools themselves or with a small group of 'preferred providers' (Institute of Education (University of London) and the National Foundation for Educational Research ( NFER), 2014). In this paper, we focus on complementary AE run by external providers for schools which serve populations facing ongoing poverty in 'austerity Britain'.

\section{Our orientation to care}

In the famous text Discipline and Punish (1977), Foucault differentiated between types of discipline which operated to maintain social order. He delineated an historical shift from violent punishment to ever more self-disciplining practices. Foucault's later work, on technologies of the self and the ethic of care of the self, elaborated the ways in which individuals might, on their own or with the help of others, discipline and groom their bodies and their conduct. Through the ethic and practice of 'caring' for the mind, body and soul, the individual strove to produce happiness, purity and wisdom (Foucault, 1982/1997, 1988). Nevertheless, incarceration and violence of various kinds always remains a possibility for the recalcitrant who refuse self-discipline. Foucault nominated schools as quintessential sites of disciplinary practice, pointing to the ways in which various regimes of surveillance, normalization and categorisation operated via punishment and reward, assessment and pedagogical approaches.

Foucauldian school studies by lan Hunter (1994) and Roger Slee $(1995,2011)$ both show the ways in which reward and punishment systems produce overt and covert resistances, with more pastoral approaches being more conducive to the production of self-managing students. John Devine's (1996) ethnography in one New York school showed how the shift to external policing produced a degree of sullen compliance but considerable alienation, truancy and failure. Kathleen Nolan (2011) came to similar conclusions in her study of the negative consequences of police in a Bronx school. 
Drawing on this body of work, we identify three school disciplinary regimes at work in English schools and in AE:

- reward and punishment systems which use continued surveillance and isolation

- team building regimes in which both bodies and minds are apparently voluntarily 're-educated' and

- the therapeutic management of the psyche and body.

We discuss these in detail later in the paper.

Foucault argued that discipline works to create norms which (re)produce what it is possible to be, see, say and know. Significant bodies of expertise and experts are created around norming disciplinary practices. School discipline for instance has its own experts and expertise, routinely included in teacher education programmes. The work of discipline 'gurus' - Bill Rogers, Sue Cowley and the like - is largely geared to the production of internalised self-discipline through the setting of rules, the creation of a positive environment, the judicious use of praise, reward and punishment and the avoidance of confrontation. However this 'common-sense' approach allows non-conforming students to be identified - see for example Maclure and colleagues on the production of students as 'problems' (Maclure, Jones, Holmes, \& Macrae, 2013) and Simon Bailey on the diagnosis of students 'with ADHD' (Bailey, 2013).

Once the variously disorderly have been identified, different bodies of expertise are deployed. Medicalised discourse practices are now synonymous with 'special education' (Harwood, 2005; Harwood \& Allan, 2014). Therapeutic approaches, often reliant on talking and various ways of 'facing reality' (Glasser, 1990), are commonly used, particularly for students who have been identified as having more generalized emotional/behavioural conduct dis-orders (Besley, 2002). There are also versions of training/conditioning regimes solely based on reward and punishment (Lewis, 2011) which emanate from the work of Skinner (1968).

The literatures on AE suggest that versions of the therapeutic largely dominate provision, with researchers frequently referring to the value that students place on having someone to talk to and a caring environment (see published literature review by Thomson, 2014). Researchers (e.g. Allan, 1996; Caulkins, 2011) also note that access to $A E$ is, for the majority of young people, via processes which both pathologise and quasi-medicalise; these processes make young people available for a range of specialised interventions.

Our paper uses and builds on this body of work. We begin with the notion that the school, as an institution, has a disciplinary regime. Our question is not whether the school has a disciplinary regime or not, nor whether the disciplinary regime is 'good' or 'bad', but rather what kind of disciplinary regime operates, and what work it does (c.f. Gore, 1993). Key to our argument is the Foucauldian understanding that power circulates and is not top down, and that subjects have some (limited) power to choose how to be and become within disciplinary regimes (Foucault, 1982). The 
harsher the disciplinary regime, the less room there is to exercise choice. The Foucauldian notion of power as positive and constitutive allows for differentiated readings of what $A E$ programme affords different students.

\section{The research}

This paper draws on data from a 2014 UK-wide study of alternative provision (Thomson \& Pennacchia, 2014). This was funded by The Princes Trust and explored how quality is understood, ensured and challenged in the AE sector. The data consisted of 17 case studies of a range of types of $A E$, including full time and long term, as well as complementary provisions (see the 17 case studies on http://www.princes-

trust.org.uk/delivery_partners_for_xl/xlmicrosite/results/whats_the_alternative.asp $x$ ). We saw programmes with a range of specialisms designed to engage young people with diverse interests; we sought quality providers that were rated well by commissioners and auditors (discussed in full in the 2014 report).

We used a common set of questions to guide both data generation and analysis across all of our sites (Yin, 1994). We wanted for example to understand how young people arrived at the provision, the everyday routines, the curriculum on offer, relations with referring schools and with families. Data generation was based on visits to sites that lasted 1-3 days, and included observation; interviews and conversations with staff and young people; photographs; and the collection of a range of documentary materials. Young people were engaged through informal conversations and focus groups, during which we sought their views on the experience of attending $\mathrm{AE}$.

We discuss here two of the English complementary provisions that we visited. We selected these because they were exceptions to the dominant pattern we observed and which we discuss next.

\section{The dominant disciplinary regime in alternative education provision}

Schools in many parts of the world are now subject to a policy agenda which compels them to focus on performance. This policy agenda is particularly advanced in England and Wales, where tests and exam results are augmented by regular external inspections. Schools are compelled to compile and keep updated a range of school data which shows how continued improvement is occurring in student learning, teaching and leadership and management. Standardised computing systems support an audit architecture which now dominates the ways in which everyday life in school proceeds (Ball, Maguire, \& Braun, 2011; Gillborn \& Youdell, 2000; Ozga, 2009).

The same accountability and audit agenda applies to $A E$, particularly that which is intended as a full time school experience either on a short or longer term basis. These AE provisions are regularly inspected, as are schools, with judgments about their success/failure drawn from a combination of some observation of practices, and a thorough perusal of paperwork. 
Our study showed that the disciplinary regimes that operated in full time AE followed the same performative pattern. As we have reported in detail elsewhere (Thomson \& Pennacchia, 2015), AE disciplinary approaches are now strongly framed by the need to 'show' what is happening to, with and for students. This has lead to student attendance and conduct being monitored, graded and graphed across lessons, days, weeks and terms. Charts and folders, both hard copy and digital, are easily/readily available for inspectors - as evidence of systematic monitoring and intervention - and for parents/regular school - as evidence of progress (of lack of it). There has also been a shift to the use of text-books and worksheets which can be similarly charted and graphed to show that alternative providers are attending to learning.

The swing to the performative has meant that $A E$, particularly but not exclusively in England, has become largely dominated by behaviourist approaches to discipline. Regimes of reward and punishment lend themselves to straightforward forms of representation in ways that talking therapeutic approaches do not. Contrary to the research literatures on $A E$, we saw a swing away from the therapeutic to reward and punishment, with talking therapies largely confined to supplementary interventions to support, and legitimate the overarching behaviourist regime. We suggest that this shift serves the interests of the AE institutions first and foremost, but does however align with the increasingly carceral approach taken to young people in welfare, employment and justice systems.

These dominant 'brownie points' systems, as we have dubbed them, offer restricted choices to students. Young people can elect to conform and be rewarded, or resist and be subject to more extreme punishments, which range from isolation to permanent exclusion. And where young people are in the youth justice system, refusal to comply in $\mathrm{AE}$ can contribute to actual incarceration.

A very small proportion of young people from full time AE provision return to their referring schools. Staff that we interviewed suggested that young people were not able to adjust to the regular school environment. We interpret this to mean that the $\mathrm{AE}$ disciplinary regimes failed to help young people to manage themselves any differently in regular school than they had before their referral. The Skinnerian regimes designed to show good $A E$ performance did not afford the kinds of selfdiscipline that are the expected norm in the regular school.

Some of the complementary provision that we saw also tended to this kind of behaviourist disciplinary regime. We did however see two other disciplinary regimes at work - team-building and therapeutic approaches. We now discuss each of these in turn, and in some detail.

\section{Major Tom's Team Builders}

Major Tom's is a "fun and fitness" programme. Run by former military personnel, it is commissioned by schools to work with groups of selected young people. Major Tom's is generally engaged by a school to work with young people who are seen to 
need additional support with educational outcomes, engagement and wellbeing. All activities take place at the commissioning school site.

We observed the programme in one 'struggling' secondary school in the Midlands a school whose GCSE results are below expectation and where there was considerable external pressure to show dramatic improvements in a short space of time. The school was one where we had previously researched alternative provision, at that time in an off-site annexe (Russell \& Thomson, 2011; Thomson \& Russell, $2007,2009)$. The headteacher had been involved in a postgraduate programme in the university and had conducted practitioner action research into disciplinary practices. The school had had no permanent exclusions for over two years (at the time we conducted this research), and was often a receiver of students who were formally excluded from other schools.

We saw the Major Tom's programme in its first year of operation in the school. The nature of the programme to be offered was negotiated by the head and placed under the supervision of the senior of two deputy heads. While the school did have a staff complement devoted to learning support, discipline was largely the responsibility of class teachers with some additional support from year level and more senior staff.

Major Tom's ran several groups within the school, all of them for students deemed likely to benefit from improvements to motivation, attendance, social interaction and so on. We were particularly interested in one group of 9 year 11 girls. The school decided to have a single sex group because these were girls who were seen by teachers and senior staff as underperforming and possessing "a range of social, emotional, behavioural and academic needs". The school felt that the programme would be "in the best interests of quickly building rapport" (Deputy Head).

Participation was not compulsory. The Deputy Head told us

The way we pitched it was: we think this will be really good for your son or daughter because ... Now it's not mandatory because it's a rewards based programme but we feel that your child, both socially, academically and emotionally they will get something out of it.

The girls we met chose to be in the programme when it was offered to them and they worked with Major Tom's for 2-3 hours each week. Their programme emphasised teamwork and peer relationships, and activities were intended to develop collaborative working, comradeship and trust. The Major Tom's instructor told us that the military ethos provided different ways of teaching, with an emphasis on "problem solving, fun, fitness and resilience". In a focus group, the girls told us that they were "probably more comfortable around girls", because they were doing strenuous physical activities such as circuit training and working together to move very heavy objects. 
The head teacher, inspired by a programme for 'naughty girls' in Australia that he had read about (Thomson, McQuade, \& Rochford, 2005a, 2005b), allowed the girls to design a uniform variation to signal their particular 'identity' - they wore jungle pants and army boots on the days in which they were involved in the programme. They also had a space within the school that they could call their own. In addition to working with Major Tom's, the school trained the girls to be cross age tutors, and they worked in the local primary school helping their younger peers with basic literacy difficulties, and in their school breakfast and after school clubs.

The girls made the most of the opportunity on offer to them and they did indeed 'turn around'. "I've calmed down a lot", one participant told us, and that made it easier for her to cope in relatively unchanged classrooms and the demands of exams. Initially apparently destined to leave school early to join the swelling ranks of local unemployed youth, the girls grew committed to finishing their time at the school and then going on to sixth form or to vocational education. As the Deputy Head put it,

... eight from nine have improved their attendance to an average for the course of ninety-two per cent. Some of those girls' average was as low as eighty-five per cent. And five of those girls, at the moment, are predicted to get five $A$ to $C$ including English and Maths. Some are slightly lower but they are all on track to hit targets now.

The programme could thus be seen to be a highly successful intervention in the trajectories of 'troubled and troublesome' girls (Lloyd, 2005).

In separate conversations with the girls, we were told that the Major Tom's instructor was:

- accepting - "We get on with him." "He knows what we're like."

- fair - "He treats us the same way as we treat him so we realise that if we didn't treat him with respect he won't do the same with us."

- encouraging - "He always says encouraging things."

- challenging - "When we, like, say we are not doing stuff he says 'yes you are doing it!"'

- flexible - "Like if we can't do something on our own they make us do it together."

- committed - "He won't give up on us." "We don't give up."

We see here the quality of relationships that are discussed in the alternative education literatures (Thomson, 2014). The girls 'get on' with the Major Tom's instructor. However, the quality of relationships is not seen as an end in themselves. The programme is not directed towards 'having someone to talk to'. Having a good relationship within the group and with the instructor is integral to the development of 'stickability' and learning the value of inter-dependent behaviour. Keeping at something, and doing it with others was seen to pay off more generally, including in schooling and future life. 
Major Tom's was presented as an offer, which the girls and their families could choose to take up. There was of course some individualising of the behavioural and academic issues facing the girls, but the programme was offered to many more than just their group of 9 . The girls were not isolated and ghetto-ised. There was official school interest in their progress - the Deputy Head took a close interest in what was happening. The school expected the girls to 'put back' for the special programme they were enjoying, and offered the additional privileges of space and clothing. In this, they were made responsible and trusted rather than being seen as deficient and incapable.

The school saw the Major Tom's programme as being about more than improving exam results and thus being of primary benefit for the school itself. The young people's participation in the programme was directed to improving life chances. As the Deputy Head put it:

Some schools unfortunately have treated it (the funding that paid for Major Tom's) as merely an extra resource just to deal with certain individuals. To some extent to lion-tame them a little bit and we're not about that...

The girls understood this commitment, as evidenced by the ways in which their positive feelings about the Major Tom's programme extended to the school itself.

... we think of it (school) as a positive thing rather than a negative thing.

This was despite nothing about the remainder of their school programme having changed. Participation in Major Tom's and the associated tutoring activities was enough to make school a place worth being, and further education more possible and desirable.

We had one nagging concern about the programme. Major Tom's is not an army recruitment programme and its staff are very clear that this is not on their agenda. Yet, in promoting 'team work, fun and fitness' as a key benefit of military service, the realities of contemporary foreign policies played out in and as war games are left un-examined. We worried about the potential for the programme to glamorise military service, and make it more desirable and achievable. At the time of writing none of the girls had elected for a military vocation and we have no information about their attitudes to defense policy and personnel more generally.

\section{Major Tom's as a disciplinary regime}

Major Tom's programme worked to defuse and reframe the girl's overt resistance to schooling. Importantly, it did not work by coercion. The programme offered a real choice. Rather than exercise their power against the school the girls could choose to be involved or not, with no apparent consequences for refusal.

We wondered why the programme appeared to be an attractive choice. 
On the surface, Major Tom's offered the girls something rather unattractive involvement in a physical training regime. We were curious about why girls for whom PE lessons were normally a site of resistance would apparently choose to engage so enthusiastically. We also noted that they appeared unconcerned about what we saw as heightened levels of surveillance - they worked in a small group under the watchful gaze of the instructor with a senior leader never too far away.

It could be argued that participation in the programme served some of the same purposes as resistance - the girls 'got out of' some lessons. And they had already been singled out as 'different' by the school's ordinary discipline regime, and the programme did not change this position. However, participation in the programme allowed the girls to simultaneously fit in and stand out. In choosing their own uniform variant - camouflage pants and military style boots - they were able to visibly, but legitimately, be other than the unattractive school uniform. Their appearance was quasi-masculinized, but referenced dress codes outside school, and in popular culture. They still stood out, but in a way that was 'on trend' but not posh/pretentious.

We also suspect that the boot camp style training appeal brought a discourse practice often seen on television into the school. Young people are now immersed in celebrity cultures, and routinely see famous women (and men) engaged in the same kind of physically testing routines that they were offered. While this activity was abnormal in school terms, strenuous physical training is norm-al in popular culture and in high profile sports such as football. Engaging in boot camp routines within the school sutured a practice that is possibly more desirable into the school assemblage. The programme allowed the girls a way to demonstrate that they were capable of hard work, a norm that many young people see as important (Allen \& Mendick, 2012). In so doing, the programme additionally expanded the ways in which it was possible to 'be' a girl in the school. The group could become 'good girls', when they worked with younger peers. Up until this time, the only way they could occupy this position was through compliance with expected school rules. This new 'responsibilising' activity showed the girls as 'deserving' of the special treatment they had received.

However, as noted, the girls were not isolated by their participation and sequestered off from the rest of the school. They were not the only group in the school engaging in the programme. Major Tom's was an 'othering' through which it was possible for the girls, and peers, to gain official approval (a reward) as well as the pleasure of seeing embodied self-improvement in levels of fitness (a disciplining of the self to provide its own internalised reward system) (c.f.Kelly \& Harrison, 2009). Importantly, the girls were not offered a whole-scale alternative curriculum. They were still expected to participate in sufficient classes to achieve their complement of GCSE subjects. They were thus still part of the overall school assemblage and not removed from its most important practice.

We understand the Major Tom's programme to have worked to expand the girls' horizons of possibility, winning their 'souls' (Rose, 1999) by offering ways in which 
they could become part of the norm, while still being 'different'. This was accomplished via an imbrication of a technology of care - physical training of the body - and an ethic of care - an opportunity for the girls to do morally approved 'good work' in the form of tutoring as well as exhibiting care for themselves. As the school expanded its disciplinary regime and brought in aspects of popular cultures as part of a practice of embodied physical and ethical re-training, the girls no longer had to exercise power against the school in order to 'become somebody' (Wexler, Crichlow, Kern, \& Martusewicz, 1992).

\section{Thursday's Child Farm}

Thursday's Child Farm provides a one-week residential programme for groups of secondary-aged pupils from across England. The young people live on the farm from Monday until Friday, accompanied by members of staff from their school. They engage in all aspects of farm life, including feeding the animals, cleaning out the enclosures, milking, and horse grooming. They help to cook all of the meals, and go for night time walks, play board games and watch films. The young people engage in a level of physical activity that would not normally be a part of their day. Alongside this increased physical exertion, the farm has dietary rules - no processed foods, sugar, and fizzy or caffeinated drinks. On the farm, young people do not have access to electronic equipment, including mobile phones.

The combination of these elements is summed-up by farm staff as a "life swap" experience for the young people. They exchange their lives back in their neighbourhoods and school for something completely different. Farm staff are sure that eliminating some of the trappings of everyday life ensures that the young people are positioned to be open to the therapeutic components of the programme, the farm's key emphasis. Young people have one-to-one time with a therapist and with other members of farm staff, and engage in a range of group counseling sessions with their peers and school staff. Meal times are crucial to the therapeutic experience and each day begins with the group eating together and reflecting on their experiences. The physical space in the farm building is designed to facilitate a 'family-living' environment, with a large table and comfortable 'lived-in' sofas.

Thursday's Child Farm aims to establish long-term relationships with schools. Their preference is for schools to nominate young people for a week on the farm in consultation with farm staff so that the aims of, and planning for, the week is shared and agreed. Thursday's Child staff attend a meeting with parents and students to explain what is on offer; participation in the programme is voluntary. School staff come to the farm with their students, and farm staff ideally also have the opportunity to brief them on the programme, its aims and processes and to debrief afterwards. Parents are invited to the fifth and last day on the farm to hear about what their children have done, and to see the farm for themselves. A farm staff member goes back to the school to pass on information about what the students have done during their week away. 
This process is something more substantial than just good information flow and communication. The school and the farm share a common goal for a particular group of young people. The teachers who also live on the farm with their students share experiences and they have changed interaction patterns and common memories that they can talk about later, thus recreating the different relationship associated with the farm. Parents too have seen for themselves something of the farm and have some new reference points for conversation. This is more than simply the provision of respite from everyday life; there are threads weaving the experience into the young people's biographies.

But, Thursday's Farm is a one-week experience and the farm staff do not want to over-claim its benefits. The resident therapist on the farm maintains that the farm experience does have an immediate impact. However, this does not carry simply and seamlessly back at school. As one staff member told us, tracking their young people suggests that

....after they leave us there is a dip, but then they improve in the medium term... that is why the schools are happy with us and we didn't lose a single school last year which is great but one of the things that you've got to manage is the expectations because the fact is that the schools expect these kids to go away and come back transformed. They are transformed when they are here, but when they go back into school they will have a lapse sometimes. One kid who has been to the farm and then struggles when they go back into school is enough for teachers to say 'well that didn't work'. But if you look around now there is no way that anyone who sees the kids could say that this hasn't had an impact on them.

The group of students we met was on the farm to improve their confidence, selfesteem, behaviour and peer relationships. Many of the twelve were very withdrawn, including two young people who rarely spoke (selective mutes). We observed the young people in the mainstream school setting at a meeting before the programme, as well as on the farm itself. The farm appeared to be a particularly potent experience for the very withdrawn.

Young people were required to 'care for' animals as soon as they arrived. Staff saw this as establishing the lived experience of caring not only for the self but also for the natural world. Animal husbandry established the interdependence of nature/people. A farm staff member explained this to us as

...attending holistically to a child in the sense that you are allowing a completely new experience for their mind, body and spirit and they are living in a community and a setting where nature and animals play a really big part in reconnecting the children to who they are.

As the young people were engaged with farm staff in everyday farm tasks, they talked one to one and in small groups about the things that they found interesting. Conversations beginning with horse grooming or gardening typically meandered 
but often included the young people's concerns, fears and worries about school, home and neighbourhood. All staff on the farm were able to engage young people in conversations that also mattered to them - topics were of mutual interest and not manufactured for the purpose of covert counselling. We were told and saw for ourselves that the starting point for conversations were the young person's own "narrative"; the purpose of dialogue was so that young people might learn to

...trust in themselves that they can talk honestly about how they feel... And we start with the children: where are they from; what do they enjoy most? It's not starting with pathology.

We did not interview the young people at the farm in the same way as we had in the Major Tom's programme. It would have been a disruption to the carefully structured programme of activities. We did however see the kinds of conversations and interactions that the young people had with both farm staff and their teachers. These were often what farm staff would describe as 'parental' and 'loving', in that the staff were genuinely interested in the young person and their current and future lives.

Farm staff worked to support school staff to carry these kinds of practices back to school.

So there is a lot of shared values between the school and us, and when their teachers come to see us they seem to be inspired by what they see and they take that back to the school (therapist)

The resident therapist meets one to one with each young person during their stay. Drawing on this meeting she offers new information to the school that they can use to modify the students' regular programmes.

I write a brief report on every child from the session that I've had with them and then we do a thing called 'school report' and that will include the celebration notes; my experience of the child in the session and a general picture of the child at the farm with any recommendations that we might make to the school. So we might say that a child's actual level of intellect is way above where she is performing and if you put her in a new environment she'll show real curiosity and interest and ability.

In optimal conditions, such as the situation we observed, there was not only an option for the young person to change but also for their school to change what they did for the young person.

\section{Thursday's Child Farm as a disciplinary regime}

Thursday's Child Farm, a 'psy' provision, aims to change young people. It claims most success with young people who are apparently compliant in school, but resist by refusing to speak or actively participate. Their choice is to withdraw their voice. 
But the formation of educated subjects requires more of students than simply being present; it requires social and verbal interaction. So these young people are identified, not by their infractions of rules, but through welfare systems that see this form of behaviour as worryingly ab-norm-al. The school's aim in nominating young people to Thursday's Child Farm is to exercise care by 'helping' young people make more of them-selves available to school regimes.

Thursday's Farm aims not to establish new physical routines but to disrupt established patterns of embodied activity. Away from the school and home, a dawn to dusk routine of physical labour combines with group activities to provide opportunities for young people to experiment with and experience another way of living, and being.

The programme's emphasis is not on learning but on everyday management and nurture. Farm workers stress health and responsibility for others - care for the self and also for animals and the land. An overt connection is made to environmental issues and the moral importance of 'care' is seen as a key to sustainability. This is an environmental discourse with which students would be familiar, but perhaps Thursday's Farm offered a unique opportunity to experience what this means as an everyday regime. Surveillance routines appear to be secondary to getting the work done. The farm's emphasis is on responsibilisation - if the cow is not milked it will suffer, if you do not eat breakfast you won't be able to work for the day. There is of course surveillance as students work individually and in small groups with farm staff: this is however framed as a learning and self-managing practice.

Young people are invited to rethink and to re-narrativise themselves. It is possible for young people to engage in many farm activities without speaking a great deal. They are not under pressure when physically working to talk, and they choose how much they say and about what. Students are offered a way to think about social interaction that is different from that of the school - they mix with others not in order to obey school rules

and become 'teachable', but to accomplish a series of morally 'good' tasks.

The therapeutic confessional is the opportunity for young people to begin to reframe them-selves in and through conversation. Young people can talk about any aspect of their home, peer and school lives, but the therapist's major focus is on the young person's sense of self and wellbeing. Using a classic talking therapies approach, she seeks to ascertain and promote self-disciplining strategies that will help young people to care for themselves as well as to adhere to school expectations and norms.

Thursday's Farm offers much the same range of opportunities to the school staff that accompany the students. They have no session with the therapist of course, but they are expected to work alongside students and establish new patterns of interaction. As teachers reveal hitherto unseen aspects of themselves, the assumption is that students will see them differently, not just as representatives of the school's disciplinary and pedagogical regimes. This allows for the possibility, 
together with some adjustment to student's individual school programmes, for students to 'take back' some of their re-learnt self-managing behaviours into the school-and home - setting.

Thursday's Farm might be seen as the furtive hand of the 'happiness industry' infiltrating schooling, taking away the focus from learning and knowledge (Ecclestone \& Hayes, 2008). However, in our view, it is part of a longer history of psy interventions that seek to bring back into the fold those who do not conform to established ways of behaving. The practice is to talk your way into a new, more norm-al life choice.

Talking as a means of steering people to 'choose' to behave differently is, in the case of Thursday's Farm, offered in conjunction with the embodied experience of acting differently for a short period of time. This might simply be a respite from school, or it might in fact be the beginning of a trigger for a more conforming self. The girls involved in Major Tom's faced overtly punitive regimes - expulsion, transfer to full time AE - if they chose not to participate and continued to mis-behave. But students in the Thursday's Farm programme were more likely to become medicalised if they continued to exercise their power as withdrawal of participation.

As is the case with Major Tom's team-building, the farm offered both a physical regime and an ethic of care. However, much more than Major Tom's Thursday's Child Farm sought to work on the 'soul' and on the ethic of caring for the self.

\section{In sum}

We began this paper with the suggestion that care was generally strongly tied to both instrumental learning and disciplinary regimes in schools. We suggested that the dominant disciplinary regimes in schools, and in alternative education, were now largely geared to instrumental ends, and worked in the interests of the school. Our research showed that in alternative education there had been a strong swing back to behaviourist reward and punishment regimes which supported this instrumentalised push.

Our analysis of two complementary AE programmes showed how they operated differently. For a start, the students were not offered a reduced curriculum, as is the case in most full-time AE. They maintained access to the national curriculum that currently counts for success and thus to the usual range of further educational options. This is certainly important, but it is not all that matters.

For us, the prime difference between Major Tom's and Thursday's Child Farm and the dominant regular school /AE regimes is in the nature of the care on offer, that is, in the choices that young people were able to make and the ways in which they could exercise power. Care in most $A E$ is highly individualised and reductively focused on obedience and performing well in set tasks. There is a relatively simple binary choice of conform/resist. By contrast, the two complementary programmes we examined offered different choices. There was no penalty for choosing not to 
participate. And the choice was not to simply conform but also to care - for others (the group, nature, children) and the self. New narratives were also on offer to explain why these choices were moral and good.

The AE programmes steered, not coerced and punished. The key to these complementary programmes, we suggest, is that the major target of student resistance - the everyday, ordinary disciplinary workings of the school - were temporarily displaced. Students were able to choose to exercise their power differently and opt into alternative ways of being and becoming. Their options were connected with wider positive moral and cultural norms and they offered different potential trajectories for the future. While these were certainly not the 'emancipation' that some might advocate, they were nevertheless more than students might have anticipated before their involvement. Whether they chose or were able to choose these futures is not the responsibility of these AE programmes, but is the job of their schools, communities and indeed, the society to which they belong.

Of course, the Foucauldian notion that 'everything is dangerous' certainly rings true. We have no desire to over-claim the benefits of the programmes. On the other hand, we cannot say that we saw no positives associated with the two programmes. Both Major Tom's and Thursday's Child Farm did seem to be somewhat different than the dominant norm, directed towards a more generous vision of education. They were not solely concerned with students achieving designated test targets, coordinating health and welfare agencies, and stopping bullying. We have no doubt that the young people themselves experienced these interventions as being 'cared for'; they were not simply performing outcomes, liabilities needing only triage to allow them to achieve better in tests. They were in schools where more humane and humanistic approaches to schooling remained strong.

Strategies and interventions, which are geared to bring students back into the mainstream of schooling, can be seen as the development of a more generous school ethos. Schools become, as Manchester and Bragg (2013) argue, more capacious, in that they are able to 'hold' many more young people within them. The capacity to enfold larger numbers of young people is integral to efforts to ensure that more of them do engage and reengage with the learning that counts towards employment, training and further study. However, this is not necessarily the same as an instrumental approach which primarily aims to meet school targets and ward off inspection sanctions.

We suggest that our analysis points to a potentially helpful way to re-consider the notion of a 'caring school' and alternative education. It is easy to suggest that schools must abandon performative disciplinary regimes where the choice is to conform or not. However they still have to keep order and students still need to learn and be taught. It is less easy to suggest what they might do instead. It is not, we have argued, a question of schools abandoning discipline, but rather what kind of disciplinary regime might be on offer. The examples of Major Tom's and Thursday's Child Farm suggest that schools might look to expand the range of 
choices open to their students. Rather than simply offering one way to choose to be part of the school, there might be more than one pattern of participation.

In moving away from thinking about whether a school is good/bad, liberatory/repressive, we propose that it might be more generative for schools - and those who research them - to consider what horizons of possibility and what possible selves are on offer to young people, and what this might allow them to be and become. This does mean looking to build a more generous and inclusive norm. It may well also mean working to combine physical as well as cognitive and affective experiences with the opportunity to act responsibly not simply for the self but for others. This is a more expansive notion of 'care' than is now often the case. 


\section{References}

Abdelnoor, A. (2007). Managed moves. A complete guide to managed moves as an alternative to permanent exclusion. London: Gulbenkian Foundation.

Allan, J. (1996). Foucault and special educational needs: A'box of tools' for analysing children's experiences of mainstreaming. Disability \& Society, 11(2), 219-234.

Allen, K., \& Mendick, H. (2012). Young people's use of celebrity: class, gender and 'improper' celebrity. Discourse, 34(1), 77-93.

Aron, L. Y. (2006). An overview of alternative education. Washington DC: The Urban Institute.

Bailey, S. (2013). Exploring ADHD: An ethnography of disorcder in early childhood. London: Routledge.

Ball, S., Maguire, M., \& Braun, A. (2011). How schools do policy. Policy enactments in secondary schools. London: Routledge.

Besley, T. (2002). Counseling youth. Foucault, power and the ethcis of subjectivity. Westport. CT: Bergin \& Garvey.

Caulkins, M. (2011). Pathways of pathology and promise in alternative education. $\mathrm{PhD}$, Simon Fraser University.

Denny, S., Fleming, T., Clark, T. C., \& Wall, M. (2004). Emotional resilience: Risk and protective factors for depression among alternative education students in New Zealand. American Journal of Orthopsychiatry, 74(2), 137-149.

Devine, J. (1996). Maximum security. The culture of violence in inner-city schools. Chicago: University of Chicago Press.

Ecclestone, K., \& Hayes, D. (2008). The dangerous rise of therapeutic education. How teaching is becoming therapy. London: Routledge.

Fielding, M. (2006). Leadership, radical student engagement and the necessity of person-centred education. International Journal of Leadership in Education, 9(4), 299-313.

Foucault, M. (1977). Discipline and punish. The birth of the prison (A. Sheridan, Trans. 1991 ed.). London: Penguin.

Foucault, M. (1982). The subject and power. In H. L. Dreyfus \& P. Rabinow (Eds.), Michel Foucault: Beyond structuralism and hermeneutics (pp. 208 - 226). Chicago: University of Chicago Press.

Foucault, M. (1982/1997). Technologies of the self. In P. Rabinow (Ed.), Ethics. Subjectivity and truth. Essential works of Foucault 1954-1984. Volume One. (pp. 223-252). New York: The New Press.

Foucault, M. (1988). Technologies of the Self: A Seminar with Michel Foucault (L. Martin, Trans.). London: Tavistock.

Gillborn, D., \& Youdell, D. (2000). Rationing education. Policy, practice, reform and equity. Buckingham \& Philadelphia: Open University Press.

Glasser, W. (1990). Quality School. Managing Students without Coercion. New York: Harper Perennial.

Gore, J. (1993). The struggle for pedagogies. Critical and feminist discourses as regimes of truth. New York: Routledge.

Guerin, G., \& Denti, L. (1999). Alternative education support for youth at-risk. The Clearing House, 73(2), 76-78.

Harris, B., Vincent, K., Thomson, P., \& Toalster, R. (2006). Does every child know they matter? Pupils' views of one alternative to exclusion. Pastoral Care in Education, 24(2), 28-38. 
Harwood, V. (2005). Diagnosing 'disorderly' children. A critique of behaviour disorder discourses. London: Routledge.

Harwood, V., \& Allan, J. (2014). Psychopathology at school: Theorizing mental disorder in schools. London: Routledge.

Hunter, I. (1994). Rethinking the school. Subjectivity, bureaucracy, criticism. Sydney: Allen \& Unwin.

Institute of Education (University of London) and the National Foundation for Educational Research ( NFER). (2013). Evaluation of the school exclusion trial (responsibility for alternative provision for permanently excluded children). London: Department for Education.

Institute of Education (University of London) and the National Foundation for Educational Research ( NFER). (2014). School exclusion trial evaluation. London: Department for Education.

Kelly, P., \& Harrison, L. (2009). Working in Jamie's kitchen. Salvation, passion and young workers. Basingstoke: Palgrave Macmillan.

Kim, J. H., \& Taylor, K. A. (2008). Rethinking alternative education to break the cycle of educational inequality and inequity. The Journal of Educational Research, 101(4), 207-219.

Lewis, C. (2011). Poststructuralism at work with marginalised children. Oak Park, UAE: Bentham Science Publishers.

Lloyd, G. (Ed.). (2005). Problem girls. Understanding and supporting troubled and troublesome girls and young women. London: Routledge.

Maclure, M., Jones, L., Holmes, R., \& Macrae, C. (2013). Becoming a problem: Baehaviour and reputation in the early years. British Educational Research Journal, 38(3), 447-471.

Manchester, H., \& Bragg, S. (2013). 'School ethos and the spatial turn: 'capacious' approaches to research and practice. Qualitative Inquiry, 19(10), 818-827.

Noddings, N. (1992). The challenge to care in schools. New York: Teachers College Press.

Nolan, K. (2011). Police in the hallways. Discipline in an urban high school. Minneapolis, MN: University of Minnesota Press.

Ozga, J. (2009). Governing education through data in England: from regulation to self evaluation. Journal of Education Policy, 24(2), 149-162.

Raywid, M. A. (1994). Alternative schools. The state of the art. Educational Leadership, 52(1), 26-31.

Rose, N. (1999). Governing the soul. The shaping of the private self (2nd ed.). London: Free Association Books.

Russell, L., \& Thomson, P. (2011). Girls and gender in alternative education provision. Ethnography and Education, 6(3), 293-308.

Skinner, B. F. (1968). The technology of teaching. Englewood Cliffs, NJ: Prentice Hall.

Slee, R. (1995). Changing theories and practices of discipline. London: Falmer.

Slee, R. (2011). The irregular school. Exclusion, schooling and inclusive education. London: Routledge.

Thomson, P. (2014). Literature Review. What's the alternatice? Effective support for young people disengaging from the mainstream. . http://www.princestrust.org.uk/pdf/Literature Review FINAL 1510 14.pdf: The Princes Trust.

Thomson, P., McQuade, V., \& Rochford, K. (2005a). "My little special house": reforming the risky geographies of middle school girls at Clifftop College. In G. Lloyd (Ed.), Problem girls. Understanding and supporting troubled and 
troublesome girls and young women (pp. 172-189). London:

RoutledgeFalmer.

Thomson, P., McQuade, V., \& Rochford, K. (2005b). "No-one's a good or bad student here": an active citizenship project as 'doing justice'. The International Journal of Learning. See http://ijl.cgpublisher.com/.

Thomson, P., \& Pennacchia, J. (2014). What's the alternative? Effective support for young people disengaging from mainstream education. http://www.princestrust.org.uk/pdf/whats-the-alternative-effective-support-for-youngpeople.pdf: The Princes Trust.

Thomson, P., \& Pennacchia, J. (2015). Hugs and behaviour points: Alternative education and the regulation of 'excluded' youth. International Journal of Inclusive Education, 10.1080/13603116.2015.1102340.

Thomson, P., \& Russell, L. (2007). Mapping the provision of alternatives to school exclusion. York: Joseph Rowntree Foundation.

Thomson, P., \& Russell, L. (2009). Data data everywhere: but not the ones that count? Mapping the provision of alternatives to exclusion. International Journal of Inclusive Education.

Vincent, K., Harris, B., Thomson, P., \& Toalster, R. (2007). Managed moves: schools collaborating for collective gain. Emotional and Behavioural Difficulties, 121(4), 283-298.

Wexler, P., Crichlow, W., Kern, J., \& Martusewicz, R. (1992). Becoming somebody. Toward a social psychology of school. London: Falmer Press.

Yin, R. (1994). Case study research. Design and methods. London: Sage. 